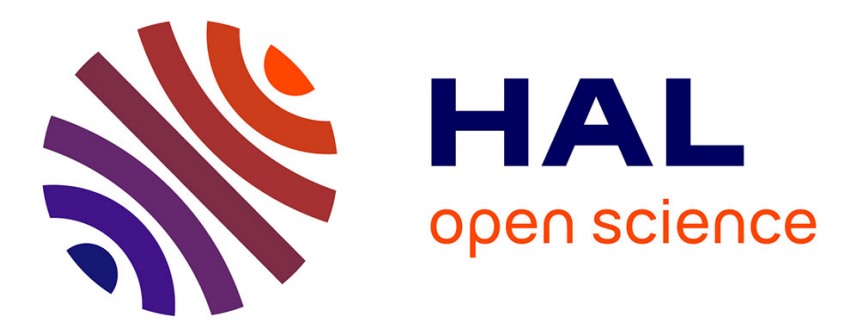

\title{
Coupled thermo-mechanical simulations of shot impacts: Effects of the temperature on the residual stress field due to shot-peening
}

Sébastien Rouquette, Emmanuelle Rouhaud, Manuel François, Arjen Roos, Jean-Louis Chaboche

\section{To cite this version:}

Sébastien Rouquette, Emmanuelle Rouhaud, Manuel François, Arjen Roos, Jean-Louis Chaboche. Coupled thermo-mechanical simulations of shot impacts: Effects of the temperature on the residual stress field due to shot-peening. Journal of Materials Processing Technology, 2009, 209 (8), pp.38793886. 10.1016/j.jmatprotec.2008.09.006 . hal-02276502

\section{HAL Id: hal-02276502 \\ https://hal-utt.archives-ouvertes.fr/hal-02276502}

Submitted on 3 Sep 2019

HAL is a multi-disciplinary open access archive for the deposit and dissemination of scientific research documents, whether they are published or not. The documents may come from teaching and research institutions in France or abroad, or from public or private research centers.
L'archive ouverte pluridisciplinaire HAL, est destinée au dépôt et à la diffusion de documents scientifiques de niveau recherche, publiés ou non, émanant des établissements d'enseignement et de recherche français ou étrangers, des laboratoires publics ou privés. 


\title{
Coupled thermo-mechanical simulations of shot impacts: Effects of the temperature on the residual stress field due to shot-peening
}

\author{
Sébastien Rouquette ${ }^{a}$ Emmanuelle Rouhaud ${ }^{b, *}$, Manuel François ${ }^{b}$, \\ Arjen Roos ${ }^{b}$, Jean-Louis Chaboche ${ }^{b}$ \\ a Université Montpellier 2, Laboratoire de Mécanique et Génie Civil, UMR 5508 CNRS, Montpellier, 34095, France \\ b Université de Technologie de Troyes, 12 Rue Marie Curie, 10000 Troyes, France
}

\begin{abstract}
A B S T R A C T
Shot-peening is an industrial surface treatment used to improve fatigue life of mechani-cal components. This process generates a compressive residual stress field on the part's surface and offers a protection against crack initiation and propagation, corrosion, etc. Although the consequences of the process on fatigue life are well known, the physical influence of the relevant parameters is not fully understood. Few of the existing shot-peening models are thus able to reproduce the correct residual stress field obtained via the actual process. This paper presents a finite element simulation of an impact includ-ing thermo-mechanical effects to investigate the influence of temperature on the residual stress field obtained through shot-peening. The influence of parameters of the process such as velocity, radius and hardness of the shot has also been studied in relation with ther-mal effects. It is observed that the temperature can reach $200{ }^{\circ} \mathrm{C}$ in the material. Further, the temperature significantly affects the residual stress field for high shot velocities. It can be concluded that shot-peening is a complex combination of physical processes, including thermal effects, which should be taken into account to better master this manufacturing process.
\end{abstract}

Keywords:

Elasto-plastic material law

Finite elements

Impact

Surface treatment

Residual stress

\section{Introduction}

Shot-peening is a cold-working process that is used to improve the mechanical characteristics of the surface of a specimen. It is employed to enhance fatigue life of turbine blades, gears, springs, etc. This process generates high compressive residual stresses in the immediate vicinity of the surface of the specimen by bombarding the surface with small shots at high velocities. These compressive residual stresses are of great interest, because they limit crack propagation. It is also well known that fatigue life improves with increasing values of the residual stress and increasing thickness of the compressive layer.

Kobayashi et al. (1998) have carried out a dynamic experiment in order to better understand the mechanism of generation of compressive residual stresses. Herzog et al. (1996) worked on the parameters influencing the residual stress field by investigating the Almen strip bending. Unfortunately the Almen intensity does not relate directly to the residual stress field induced by shot-peening. Analytical approaches have been used to determine the stress distribution and the thickness of the compressive layer. Al-Hassani 
(1981) has established an analytical solution to estimate the contact time and the average contact pressure for a shot impacting a semi-infinite body. Al-Obaid (1990) has expressed the depth of the plastic zone according to the shot radius, shot velocity and the average pressure computed from Hertz theory. Baragetti and Terranova (2000) have proposed analytical equations predicting the residual stress field of shot-peening based on non-dimensional analyses. Fathallah et al. (1998) have proposed an analytical model of shot-peening using a simplified analysis of the plastic behavior of metals detailed in Zarka et al. (1990). Starting with the early work of AlObaid $(1991,1993)$ using finite elements, several numerical analyses have been proposed to simulate the shot-peening process. Schiffner and Droste gen. Helling (1999) made a 3D analysis of multiple shot impacts and they concluded that adjacent shots had a significant effect. Rouhaud and Deslaef (2002) proposed a simulation of one or several impacts studying the influence of shot and specimen parameters on the residual stress field. Meguid et al. (2002) investigated shot hardness, strain rate effects and coverage using 3D finite element models. Majzoobi et al. (2005) have investigated multiple shot impacts and the effect of the shot velocity on the residual stress profile. Rouhaud et al. (2005) in a review on shot-peening modeling showed that the maximal values of the compressive residual stress are most often overestimated in numerical models, when Klemenz et al. (2006) presented finite element simulations comparing well with experimental data.

These studies involved the mechanical aspect of the process whereas the heat dissipation resulting from the plastic deformation of the specimen was not investigated. Hardly any thermo-mechanically coupled approaches of a specimen impacted by a shot exist in the literature. However, it was shown that the control of temperature during the shotpeening treatment could affect the final state as noticed Harada and Mori (2005); they indeed showed that an adequate working temperature can be defined to obtain higher hardness and compressive residual stresses. Kirk (2003) showed that Almen strips temperature could increase up to $62^{\circ} \mathrm{C}$ when peened with cast steel shots.

In this paper, therefore, the coupled thermo-mechanical problem of the normal impact of a shot on a semi-infinite specimen is investigated. There are several objectives:

- Establish whether thermal effects induced by impacts affect the residual stress field; indeed, the preliminary work of Rouquette et al. (2005) on the temperature field motivates a more systematic thermo-mechanical study.

- Better understand the relevant physical processes that occur during shot-peening, which could also be generalized to other types of impacts, such as impacts of foreign objects, in particular in the range of intermediate velocities.

- Investigate the potential application of temperature field measurement for process quality control, as proposed by Pron et al. (2002).

The first part of this work motivates the interest of studying the temperature effects during a shot impact. Then, the influence of the shot parameters on the temperature and the subsequent residual stresses fields are presented and discussed.

\section{Model of the impact}

In what follows, a simulation of the impact of a shot on a thermo-elasto-plastic specimen is performed by dynamic finite element analysis. The specimen is made out of $35 \mathrm{NiCrMo15}$ steel, which was chosen because it is a material often shot-peened in industry. The problem is axi-symmetric (Fig. 1 represents the geometry). The specimen is modeled by a $3 \mathrm{~mm} \times 3 \mathrm{~mm}$ square, chosen sufficiently large to avoid boundary effects on the residual stress and the temperature fields. The mesh contains quadratic reduced finite elements with 5622 nodes and the smallest element size is $3 \mu \mathrm{m}$.

The mechanical and thermal boundary conditions are represented in Fig. 1. The upper surface of the specimen is subjected to convective exchanges with the surroundings. The convection coefficient is taken from the work of Petit and Taine (1998), and set to $20 \mathrm{~W} /\left(\mathrm{m}^{2}{ }^{\circ} \mathrm{C}\right)$. It is assumed that the contact duration between the shot and the specimen is very short as compared with the heat diffusion time constant, thus thermal exchanges are not allowed between them. The initial temperature of the system is room temperature $\left(20^{\circ} \mathrm{C}\right)$. The radii and initial velocities of the shot are chosen to be representative of the shot-peening process.

The heat conduction equation coupled to the mechanical problem is

$\rho C_{\mathrm{p}} \frac{\partial \mathrm{T}}{\partial \mathrm{t}}=\operatorname{div}(k \operatorname{grad}(\mathrm{T}))+\beta\left(\sigma:{\underset{\sim}{\dot{\varepsilon}}}^{\mathrm{p}}\right)$

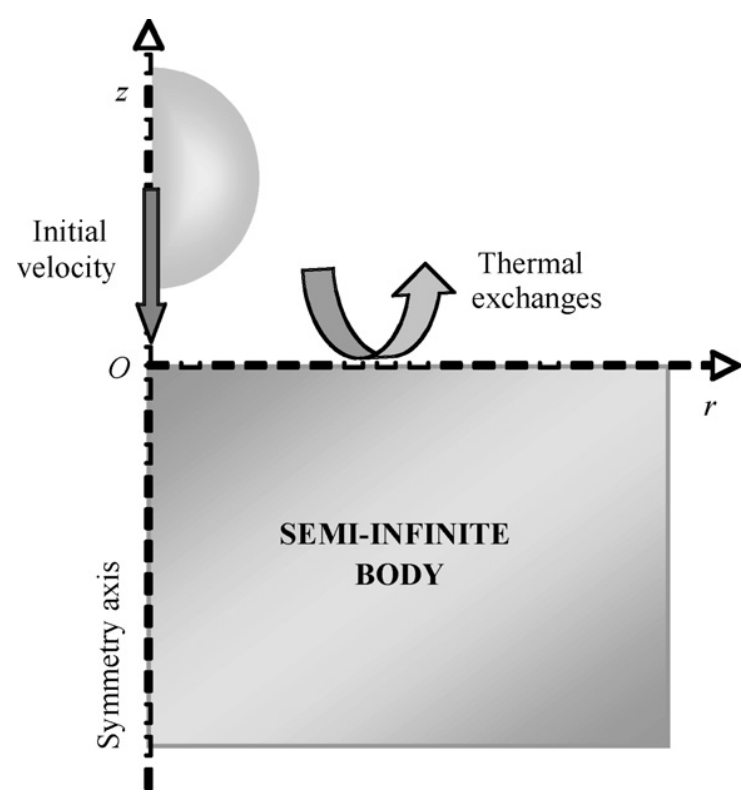

Fig. 1 - Boundary conditions of the thermo-mechanical problem. Thermal exchanges are possible at the upper surface of the specimen. Thermal exchanges between the shot and the specimen are not possible. The problem is axi-symmetric and the specimen is semi-infinite. An initial velocity is given to the shot, and the initial temperature is set to $20^{\circ} \mathrm{C}$ throughout the system. 
where $\mathrm{T}$ is the temperature, $\mathrm{t}$ is the time, $\sigma$ is the Cauchy stress tensor, $\underset{\sim}{\dot{\varepsilon}}$ is the rate of plastic deformation, $\rho$ is the density, $k$ is the thermal conductivity, $C_{\mathrm{p}}$ is the specific heat and $\beta$ is a dimensionless coefficient expressing the fraction of plastic work dissipated as heat. Kapoor and Nemat-Nasser (1998) present experiments with the Hopkinson bar technique in order to evaluate the amount of plastic work that is converted into heat. They concluded that $70 \%$ of the work was converted into heat when a Tentalum alloy was submitted to a strain rate value of $3000 \mathrm{~s}^{-1}$. Rosakis et al. (2000) have worked on the experimental determination of the coefficient $\beta$; they have shown that its value varies between 0.8 and 1.0 according to the material and the strain rate investigated. This parameter is fixed at $\beta=0.9$ in the computations presented in the present work. The mechanical and thermal parameters are assumed to be independent of the temperature because temperature variations are expected to be moderate (below $\left.200^{\circ} \mathrm{C}\right)$.

The specimen is assumed to have a thermo-elasto-plastic constitutive law. The shot is assumed to be either perfectly rigid or purely elastic with the same elastic parameters as the specimen. The constitutive law of the specimen contains two non-linear isotropic hardening terms that have been chosen as proposed by Lemaître and Chaboche (1994):

$\sigma=\sigma_{\mathrm{Y}}+\mathrm{Q}_{1} \mathrm{e}^{-b_{1} p}+\mathrm{Q}_{2} \mathrm{e}^{-b_{2} p}$

where $Q_{1}, b_{1}, Q_{2}$ and $b_{2}$ are hardening parameters, $\sigma_{\mathrm{Y}}$ is the yield stress, and $p$ the cumulated plastic strain, defined as

$p=\int_{0}^{t} \sqrt{\frac{2}{3} \dot{\varepsilon}^{p}: \dot{\varepsilon}^{p} \mathrm{dt}}$

The values of the mechanical and thermal parameters for the 35NiCrMo16 steel are presented in Table 1. Computations were performed with the finite element code Z-Set (NW Numerics website). An implicit method is used to solve the dynamic thermo-mechanical problem.

In the following text, the thermo-mechanical results are compared to purely mechanical results obtained under the same conditions. Thus, in the template of the figures, symbol "TM" means thermo-mechanical coupling, whereas symbol

\begin{tabular}{lc} 
Table $\mathbf{1}$ - Mechanical and thermal parameters of the \\
specimen. \\
Mechanical parameters & Value \\
\hline Young's modulus $E(\mathrm{GPa})$ & 210 \\
Yield stress $\sigma_{\mathrm{Y}}(\mathrm{MPa})$ & 950 \\
Poisson ratio $v$ & 0.3 \\
Thermal expansion coefficient $\alpha\left(\mathrm{K}^{-1}\right)$ & $12 \times 10^{-6}$ \\
Density $\rho\left(\mathrm{kg} / \mathrm{m}^{3}\right)$ & 7900 \\
Thermal conductivity coefficient $k(\mathrm{~W} /(\mathrm{m} \mathrm{K}))$ & 45 \\
Specific heat $\mathrm{C}_{\mathrm{p}}(\mathrm{J} /(\mathrm{kg} \mathrm{K}))$ & 450 \\
Global exchange coeficient $h_{\text {global }}\left(\mathrm{W} /\left(\mathrm{m}^{2} \mathrm{~K}\right)\right)$ & 20 \\
$\mathrm{Q}_{1}$ saturation hardening coefficient $(\mathrm{MPa})$ & 50 \\
$b_{1}$ saturation rate coefficient $($ dimensionless) & 1000 \\
$\mathrm{Q}_{2}$ saturation hardening coefficient $(\mathrm{MPa})$ & 100 \\
$b_{2}$ saturation rate coefficient $($ dimensionless) & 50 \\
\hline
\end{tabular}

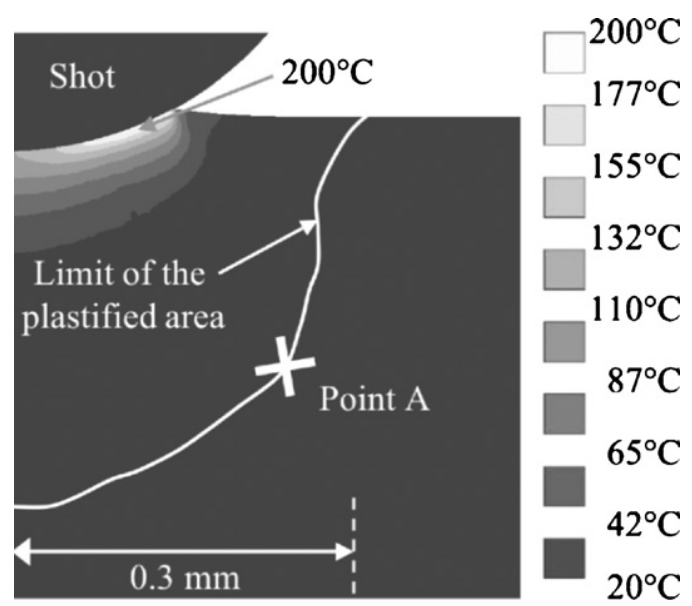

Fig. 2 - Temperature field and plastic zone obtained for a rigid shot of radius $0.3 \mathrm{~mm}$ and velocity of $80 \mathrm{~m} / \mathrm{s}$ at the instant of maximal penetration of the shot.

"M" denotes a mechanical computation without any thermal effects.

\section{Temperature field in the impacted material}

The temperature field is first analyzed for a thermomechanical problem corresponding to the impact of a rigid shot with a radius equal to $0.3 \mathrm{~mm}$ and a velocity of $80 \mathrm{~m} / \mathrm{s}$. In this case, the total duration of the impact is $0.98 \mu \mathrm{s}$ and the penetration of the shot reaches its maximum $0.6 \mu \mathrm{s}$ after the onset of the impact. Fig. 2 presents the temperature field at this instant, whose maximal value reaches $200^{\circ} \mathrm{C}$. The temperature falls from 200 to $20^{\circ} \mathrm{C}$ over a distance of $0.15 \mathrm{~mm}$. At this instant, the spatial thermal gradient is quite significant (over $1200^{\circ} \mathrm{C} / \mathrm{mm}$ ) and the generated heat is confined inside the plastified area identified in Fig. 2 and has not diffused yet. The time scale for heat diffusion is indeed higher than the duration of the impact. The approximation supposing that the thermal exchanges between the shot and the specimen are small is thus validated here.

Fig. 3 shows the time evolution of the temperature at two points selected in the volume of the impacted part (the center of the impact and the point A localized on Fig. 2), for both a rigid and an elastic shot. For a rigid shot, at the center of the impact (Fig. 3a), the temperature reaches $135^{\circ} \mathrm{C}$ in around $0.6 \mu \mathrm{s}$, which corresponds to the time at which the shot reaches its maximal penetration. At this point, the temperature increases during the contact between the shot and the part, due to the plastification effects in this area, then it decreases through diffusion effects. The maximal temperature at point $\mathrm{A}$ is $22.5^{\circ} \mathrm{C}$ (Fig. 3b). Point $\mathrm{A}$ is located on the boundaries of the plastified area, as indicated on Fig. 2 . The temperature rise appears 20-25 $\mu$ s after the end of the impact and it reaches its maximal value $1100 \mu$ s after the onset of the impact. At point $A$, the temperature increase is due to heat diffusion rather than energy dissipation. The effects of diffusion are thus small, since point $A$ is located at the limit of the plastic zone and only sees an increase in temperature of $2.5^{\circ} \mathrm{C}$. 
(a)

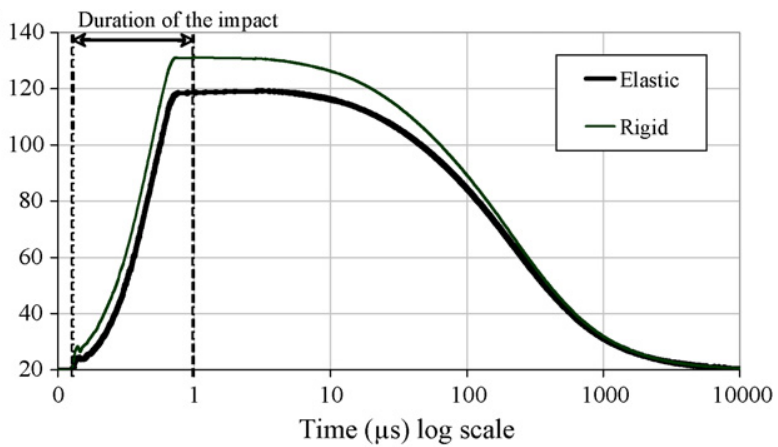

(b)

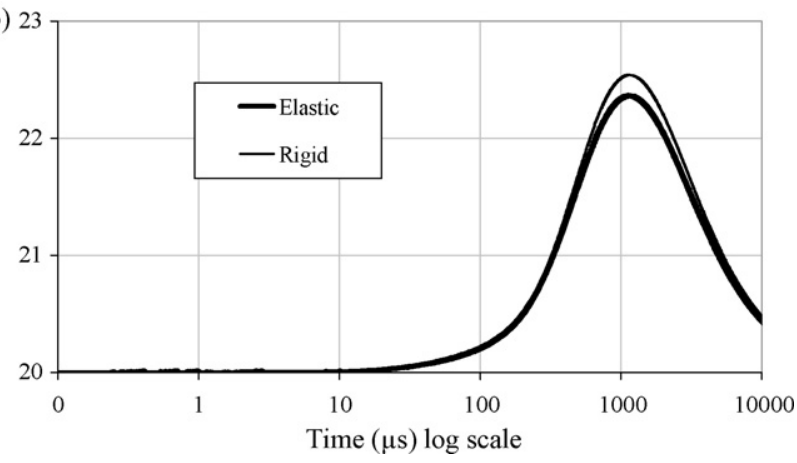

Fig. 3 - Time evolution of the temperature for (a) the origin of the coordinate system and (b) at point A (see Fig. 2 for the location of point $A$ ). The specimen is impacted by a rigid or an elastic shot. The shot radius is $0.3 \mathrm{~mm}$ and the shot velocity is $80 \mathrm{~m} / \mathrm{s}$. It should be noted that the temperature scales of the two figures are very different.

For an elastic shot, the temperature evolution is very similar to the one observed with a rigid shot, but the maximal values differ slightly. It can thus be concluded that two time scales appear for the temperature evolution:

- The impact itself, when heat is generated but remains confined to the plastic zone. The typical duration is $1 \mu \mathrm{s}$.

- The heat diffusion through the rest of the specimen. The typical duration is $1-10 \mathrm{~ms}$, i.e. $1000-10,000$ times longer than the impact.

\section{Effects of the temperature on the residual stress field}

The time evolution of the radial stress computed is further presented on Fig. 4 for the point located at the center of the impact (origin of the coordinate system). The radial stress obtained for the thermo-mechanical simulation of the rigid shot impact presented above is compared to the one obtained with a computation neglecting any thermal effects, the other parameters being left unchanged. It is interesting to note that during the first part of the simulation (before $100 \mu \mathrm{s}$ ), there is no difference between the two cases. Then, the stress reaches a stable value of $-960 \mathrm{MPa}$ in the purely mechanical case, while it reaches $-800 \mathrm{MPa}$ when thermal effects are accounted for. From Fig. 3, it can be seen that the decrease of the temperature at the origin becomes significant $30 \mu$ s after the impact. Thus,

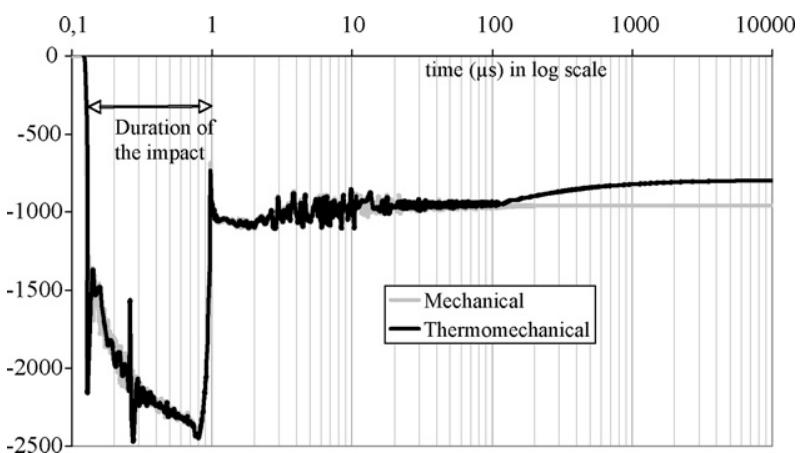

Fig. 4 - Evolution of the radial stress as a function of time for the thermo-mechanical system and the problem without any thermal effects. The stress is taken at the point located at the origin of the coordinate system. The shot is rigid, its radius is $0.3 \mathrm{~mm}$ and its velocity is $80 \mathrm{~m} / \mathrm{s}$.

it is the heat dissipation during the cooling phase that modifies the residual stresses. Similar results have been observed for other points of the shot-peened specimen. In the end, the difference between the radial stresses reaches about $160 \mathrm{MPa}$, which is quite significant.

Fig. 5 presents the radial residual stresses obtained for a problem corresponding to the impact of a rigid or elastic shot with a radius equal to $0.3 \mathrm{~mm}$ and a velocity of $80 \mathrm{~m} / \mathrm{s}$. The figure presents the stress profile on the symmetry axis of the semi-infinite specimen, plotted when it has recovered its initial temperature. The coupled thermo-mechanical case is compared to a purely mechanical elasto-plastic computation. The coupled thermo-mechanical computations give a radial stress profile with lower compressive stresses than their purely mechanical counterparts. This difference decreases with increasing depth and is significant up to the maximal value of the residual stress. It can be noticed that the depth at which the maximal residual stress occurs does not change with the effects of temperature but that its maximal value has decreased by about $45 \mathrm{MPa}$. Near the surface of the specimen, the difference between the two solutions is above $150 \mathrm{MPa}$. The solutions obtained for the rigid and elastic shots are

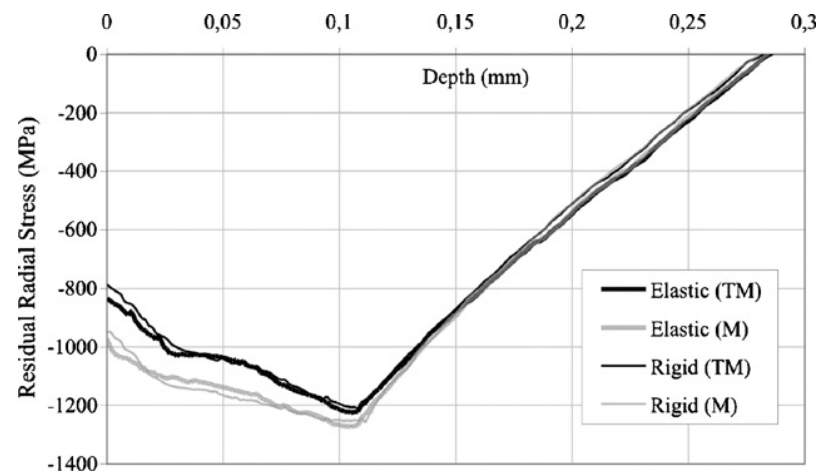

Fig. 5 - Radial residual stress profiles on the symmetry axis versus depth for thermo-mechanical and mechanical simulations; comparison between a rigid and an elastic shot. The shot radius is $0.3 \mathrm{~mm}$ and the velocity of the shot is $80 \mathrm{~m} / \mathrm{s}$. 
very similar; this point is further discussed in the following section.

Even though the temperature increase is not high enough to change the mechanical properties of the material, a significant effect is observed on the final residual stress levels. The effect of temperature on the residual stresses is due to two different physical processes:

- The heat production due to plastic strain, which is rapid (1 $\mu$ s, see Fig. 3).

- The thermal diffusion, which is much slower $(10 \mathrm{~ms}$, see Fig. 3).

Because of this difference in time scales, the value of the temperature at the instant of maximal penetration of the shot is representative of the cumulated plastic strain energy. The decrease in temperature and its local gradient leads to a relative shrinkage of the plastified material, which in turn decreases the absolute values of the residual stresses.

The high values observed in the residual stress and hardening effects leading to maximal residual stress values above the yield stress values are classically obtained in single impact simulations as presented in the review about shot-peening models of Rouhaud et al. (2005). It is important to note that thermal effects tend to reduce this residual stress, even for a single impact.

\section{Influence of the material model chosen for the shot}

In the actual shot-peening process, the shot is not rigid but only a little harder than the shot-peened part. Although the easiest solution is the rigid shot model in finite element codes, elastic shot models seem to be a good compromise (compared to elasto-plastic models of the shot itself). It is thus interesting to see how the model chosen for the shot (rigid or elastic) influences the thermal effects observed. In the simulation presented, the effects of a rigid shot versus an elastic shot model (the characteristics of the peened specimen being left unchanged) are evaluated and compared.

Figs. 3 and 6 compare temperatures obtained for the rigid and elastic shots. Fig. 3 shows the evolution of the temperature as a function of time at two points selected in the volume of the impacted part. Clearly the rigid shot induces a higher temperature in the impacted part. Fig. 6 shows that the temperature generated by the rigid shot is significantly higher at the surface of the specimen, where the difference with the elastic shot reaches $35-40^{\circ} \mathrm{C}$. Below the surface, this difference decreases. At maximal penetration of the shot, the initial kinetic energy of the shot is entirely transferred to the impacted part in the case of a rigid shot, whereas it is shared between the shot and the part for an elastic shot. Fig. 7 shows the deformed shape of the elastic shot at the instant of maximal penetration. Consequently, with the elastic shot the plastic strain in the part is smaller and therefore less heat is generated, leading to a lower temperature field.

Although Fig. 5 shows that the rigid or elastic nature of the shot does not significantly influence the residual stress profiles in the case presented here, it clearly affects the tem-
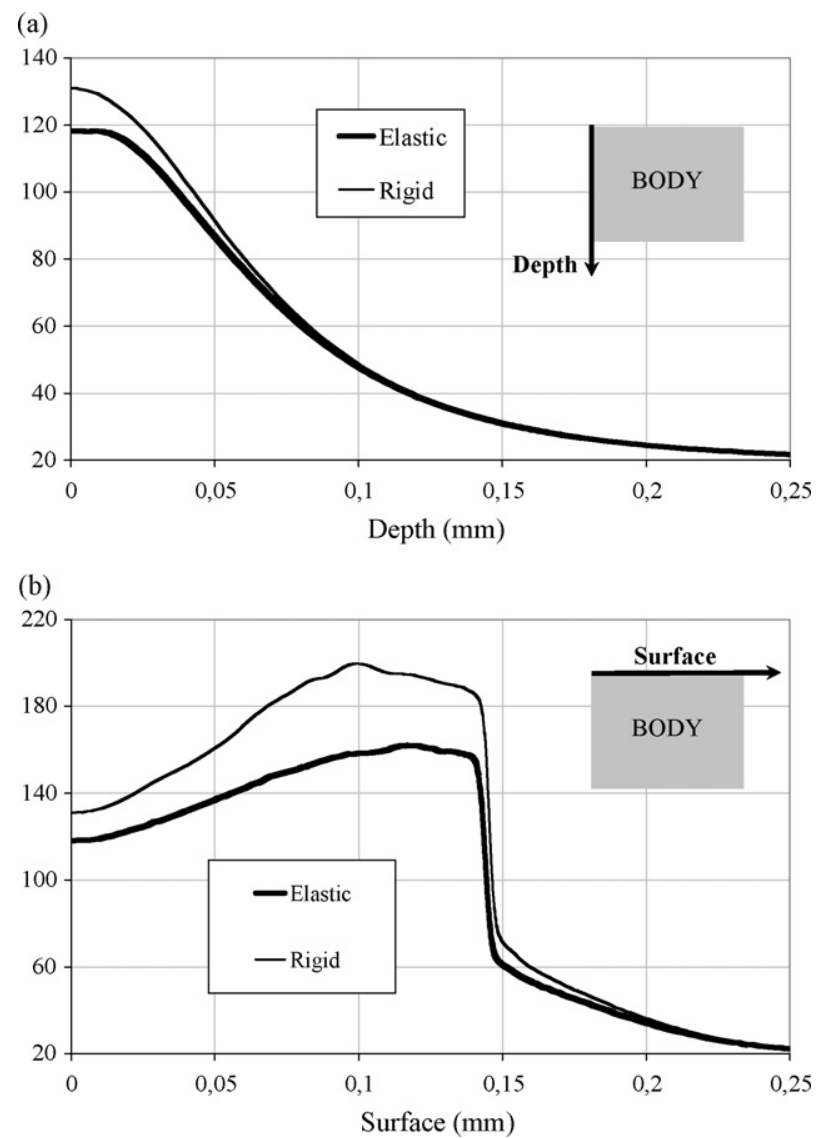

Fig. 6 - Evolution of the temperature on the symmetry axis versus depth (a), and on the surface of the specimen (b), at the maximal shot penetration; comparison between a rigid and an elastic shot. The shot radius is $0.3 \mathrm{~mm}$ and the velocity of the shot is $80 \mathrm{~m} / \mathrm{s}$.

perature fields. It is thus reasonable to consider that the elastic shot model offers a good representation of the actual process, as discussed by Rouhaud and Deslaef (2002). In the work presented below, the influence of the other parame-
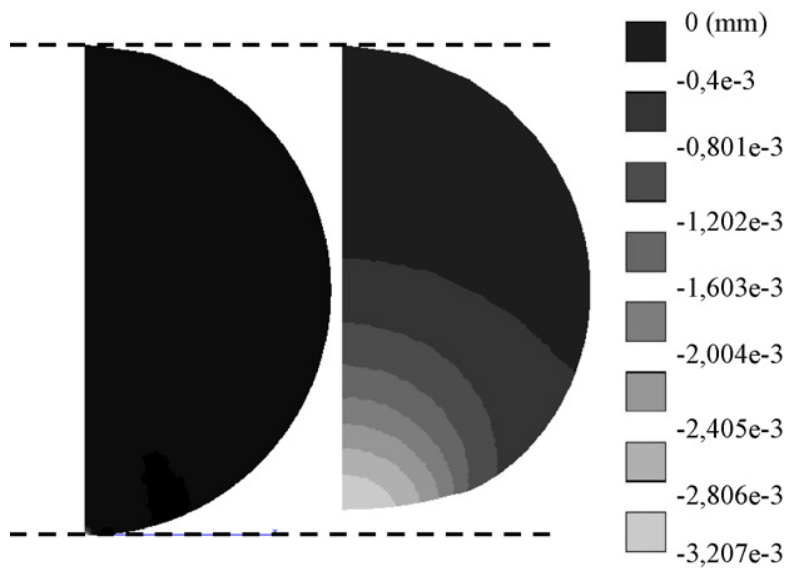

Fig. 7 - Original and deformed shape of the elastic shot at the maximal penetration (for clarity, the displacements have been magnified 10 times for the deformed shape). The legend represents the vertical displacement. 
(a)
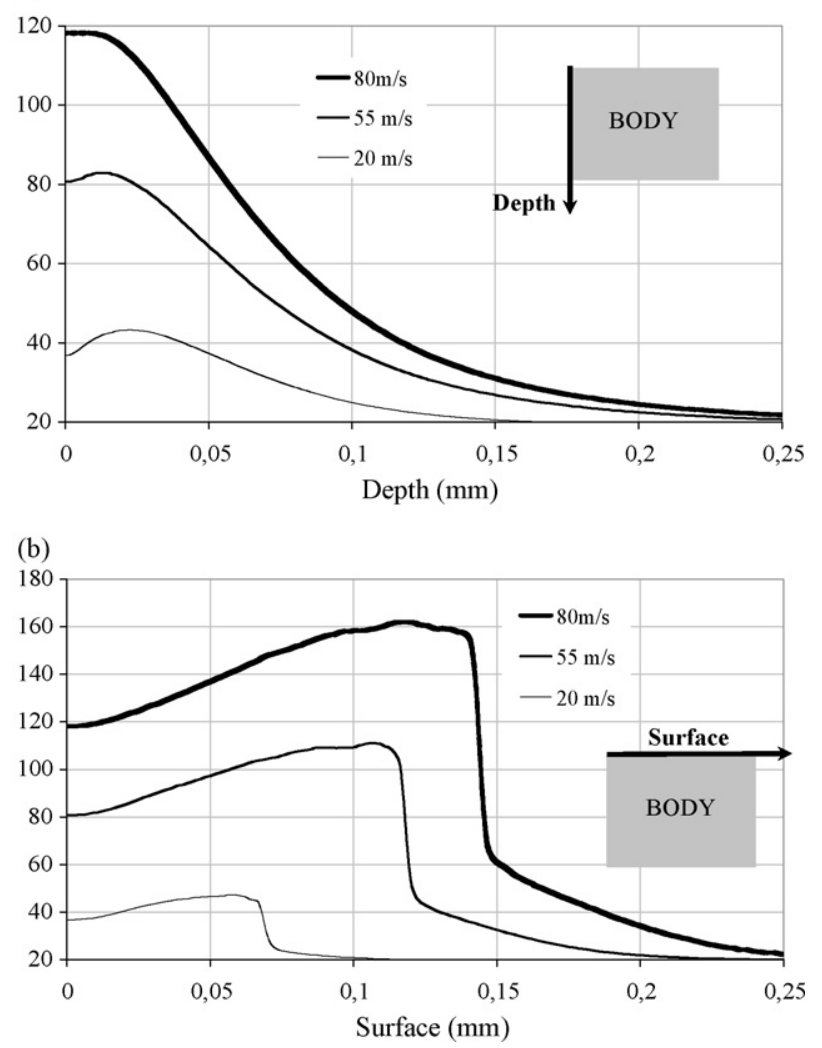

Fig. 8 - Evolution of the temperature on the symmetry axis (a) and on the surface of the specimen (b) at the instant of maximum shot penetration. The radius of the shot is $0.3 \mathrm{~mm}$.

ters of the model has been thus investigated for elastic shots only.

\section{Influence of the velocity of the shot}

The influence of shot velocity is studied for elastic shots with initial velocities equal to 20,55 and $80 \mathrm{~m} / \mathrm{s}$. Fig. 8 presents resulting temperature fields. The heat generated in the specimen is considerably affected by the shot velocity: while the increase in temperature is around $25^{\circ} \mathrm{C}$ for a shot with a velocity of $20 \mathrm{~m} / \mathrm{s}$, it reaches $100^{\circ} \mathrm{C}$ for a shot with a velocity of $80 \mathrm{~m} / \mathrm{s}$. Similar results are obtained for the temperature on the surface of the specimen.

Fig. 9 shows the residual radial stress profile obtained at the axis of symmetry of the system when the material has returned to room temperature. The residual stress is clearly affected by the velocity: the maximal absolute value of the stress and the depth of the layer with a compressive residual stress increases with increasing velocity. These facts are coherent with common observations of the shot-peening process. The differences between the thermo-mechanical and mechanical solutions increase with shot velocity. However, they become negligible at low velocities and beyond the depth of maximal stress.

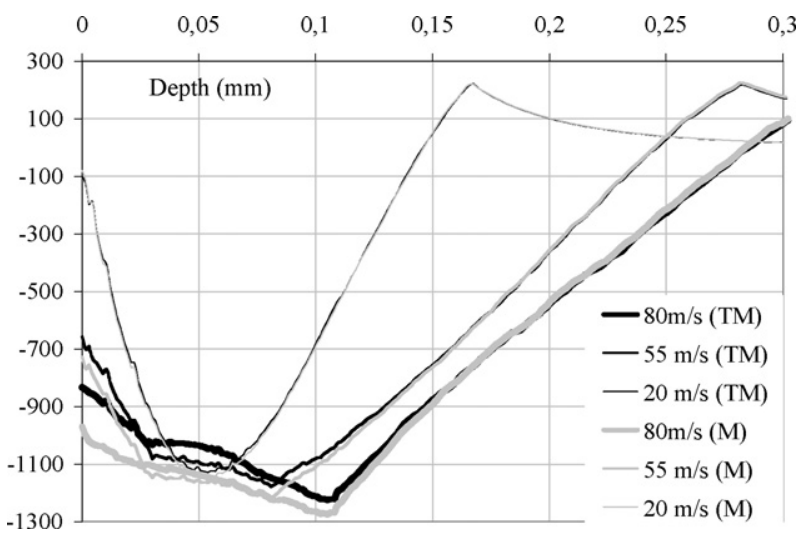

Fig. 9 - Radial stress profile on the axis of symmetry of the specimen for several shot velocities and for thermo-mechanical and mechanical simulations. The shot radius is $0.3 \mathrm{~mm}$.

\section{Influence of the radius of the shot}

In the shot-peening process, several shot sizes are used. This section is therefore dedicated to the influence of the shot radius on thermo-mechanical computations. A constant shot velocity of $80 \mathrm{~m} / \mathrm{s}$ has been used for all cases. The shot radii are equal to $0.15,0.3$ and $0.45 \mathrm{~mm}$.

Fig. 10 shows the temperature field at the instant of maximal shot penetration. The radius of the shot influences significantly the size and temperature values of the field. The highest temperature $\left(185^{\circ} \mathrm{C}\right)$ is obtained for the smallest shot associated with a small volume affected by the temperature rise. The biggest shot affects a much larger volume with a highest temperature of $165^{\circ} \mathrm{C}$. The three shots have the same velocity, hence the kinetic energy of the large shot is higher and these results might appear contradictory. Therefore, for each case, the energy flux through the impacted surface was calculated. The energy flux is defined as: $m_{S} V_{S}^{2} / 2 \Delta t S$ where $m_{S}$ and $V_{S}$ are the shot mass and velocity, $\Delta t$ represents the duration of the impact and $S$ is the highest area reached by the contact surface between the shot and the specimen. The relevant results are gathered in Table 2. Clearly, the highest energy flux is obtained for the smaller shot.

Fig. 11 shows the evolution of the temperature as a function of the time for two points of the semi-infinite specimen. The

Table 2 - Comparison of relevant values for several shot radii.

\begin{tabular}{lllllll}
\hline Shot radius $(\mathrm{mm})$ & 0.15 & 0.3 & 0.45 & & \\
Mass $(\mu \mathrm{g})$ & 0.110 & 0.882 & 2.98 & & \\
Kinetic energy $(\mathrm{mJ})$ & 0.352 & 2.82 & 9.52 & & \\
Impact radius $(\mu \mathrm{m})$ & 69.0 & 149 & 221 & & \\
Impact area $\left(\mu \mathrm{m}^{2}\right)$ & 14,957 & 69,746 & 153,438 & & \\
Impact duration $(\mu \mathrm{s})$ & 0.44 & 1.06 & 1.6 & & & \\
Impact energy flux & 53,600 & 38,200 & 38,800 & & & \\
$\quad\left(\mathrm{MW} / \mathrm{m}^{2}\right)$ & & & & & & \\
$\quad$ Surface residual & $\mathrm{M}$ & $\mathrm{TM}$ & $\mathrm{M}$ & $\mathrm{TM}$ & $\mathrm{M}$ & $\mathrm{TM}$ \\
$\quad$ stress $(\mathrm{MPa})$ & -1000 & -905 & -970 & -830 & -975 & -750
\end{tabular}

The values are estimated when the shot reaches its maximum depth into the specimen. The shot velocity is $80 \mathrm{~m} / \mathrm{s}$. 

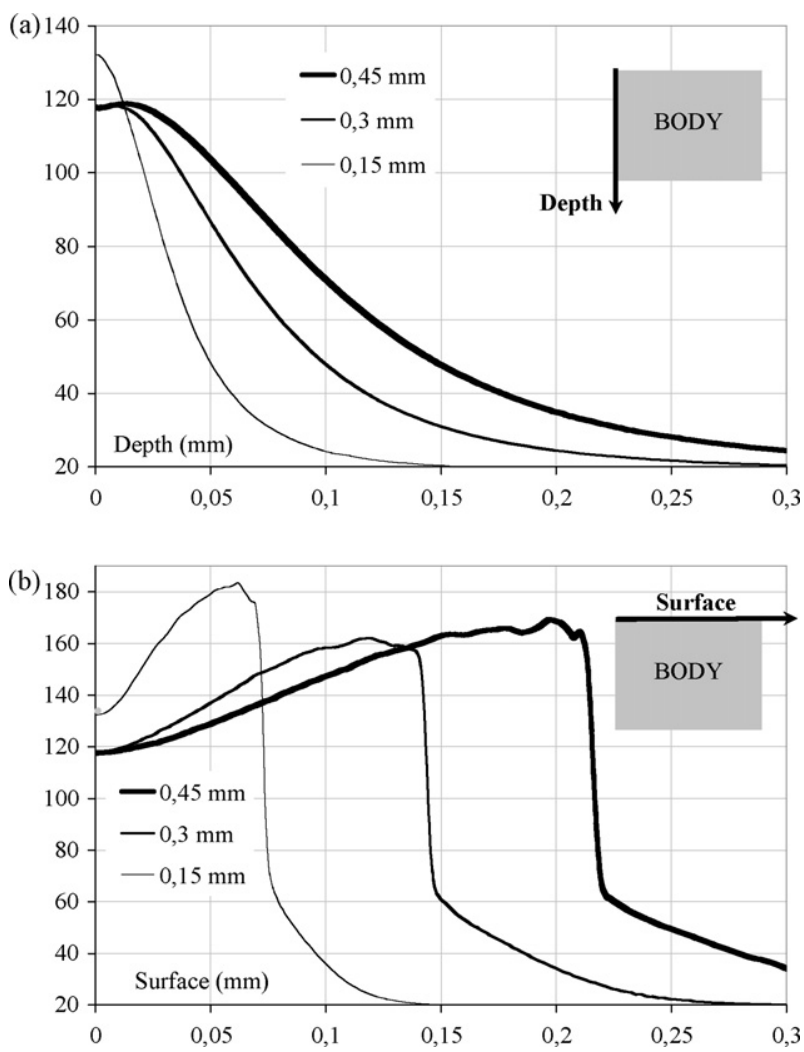

Fig. 10 - Evolution of the temperature on the symmetry axis (a) and at the surface of the specimen (b) at the instant of maximal shot penetration, for different shot radii. The shot velocity is $80 \mathrm{~m} / \mathrm{s}$.

duration of the impacts is $0.44 \mu \mathrm{s}$ for the small shot, $1.06 \mu \mathrm{s}$ for the medium shot and $1.6 \mu \mathrm{s}$ for the large shot. For the smallest shot, the decrease in temperature at the center of the impact starts immediately after the end of the impact whereas for the two other cases the temperature remains stable for $10 \mu \mathrm{s}$ before decreasing. It is the diffusion of the heat from the other points of the plastified volume that maintains the center of the impact at a constant temperature for this period of time. For the small shot, the volume that is heated is relatively small (as seen on Fig. 10), and is rapidly cooled down by thermal diffusion; point A is barely affected by the temperature for the small shot (Fig. 11b). For the medium shot, the curves are similar to the small shot qualitatively; for the large shot, the temperature evolution at point $A$ is qualitatively different from the other cases: the initial temperature is due to plastic effects during the impacts: at $t \approx 0.55 \mu$ s the plastic front reaches this particular point. Then, the heat diffusion effects appear for $t>100 \mu \mathrm{s}$.

Fig. 12 presents the residual radial stress profile after the impacts. As observed previously, the difference in radial stress profiles between thermo-mechanical and mechanical computations decreases until the maximum compressive stress is reached. For each case, the radial stress values at the surface of the specimen are reported in Table 2. At constant shot velocity, one may notice that with increasing shot radius, the radial stress value at the surface increasingly deviates from the problem without thermal coupling. For the small shot, the thermal

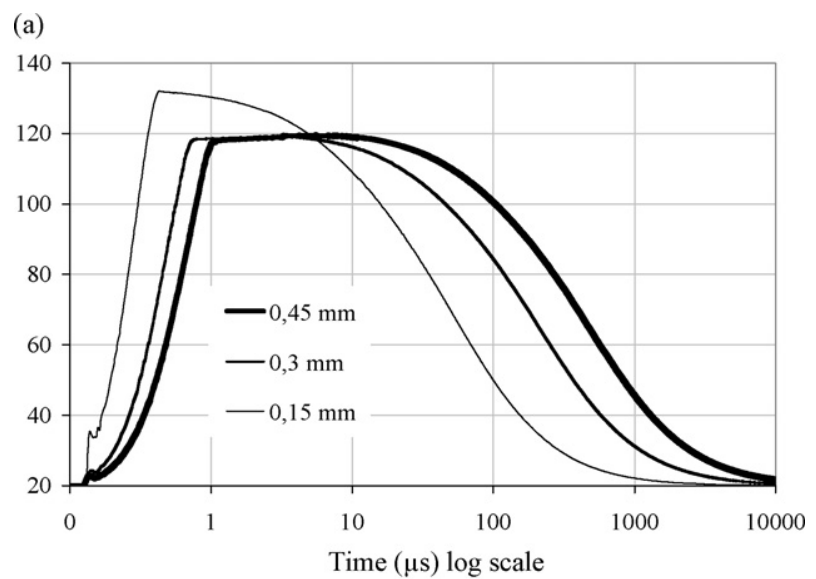

(b)

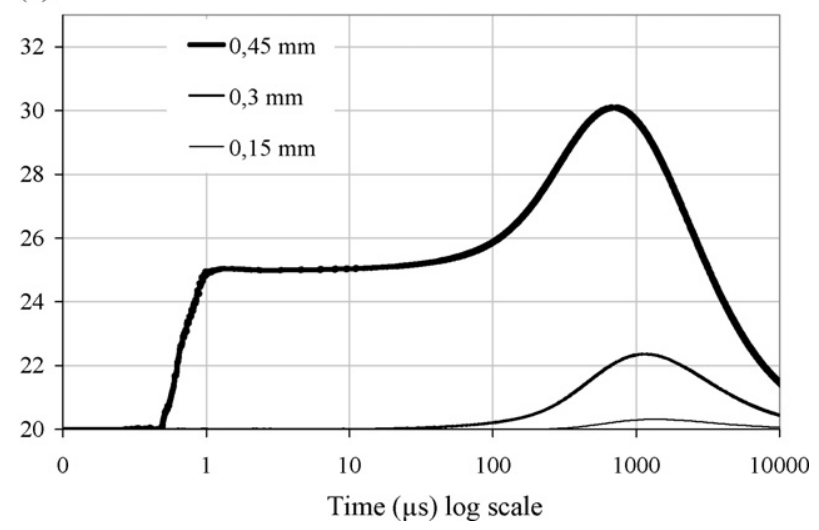

Fig. 11 - Time evolution of the temperature for the point located at the origin of the coordinate system (a) and at point $A(b)$ for different shot radii. See Fig. 2 for the location of point $A$. The shot velocity is $80 \mathrm{~m} / \mathrm{s}$.

effects on the residual stresses are negligible. While it is in this case that the temperature is the highest, the small sizes of the plastic zone and thus the heated volume contributes little to a change in the residual stress state. With increasing shot radius (at constant velocity of $80 \mathrm{~m} / \mathrm{s}$ ), the volume affected by the temperature increases, and the thermal effects affect the residual stresses significantly.

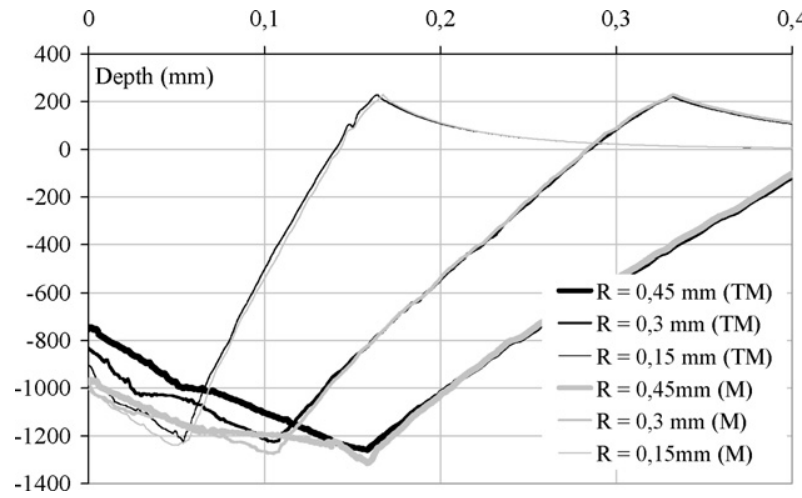

Fig. 12 - Radial stress profile on the symmetry axis of the specimen for different shot radii. The shot velocity is $80 \mathrm{~m} / \mathrm{s}$. 


\section{Conclusion}

The effect of shot-peening parameters such as the model for the shot, the shot radius and the shot velocity were further investigated. Increasing the shot velocity induces more plastic deformation in the specimen, thus generating higher temperatures. This, in turn, reduces the radial stress at the surface. Also, an increase of the shot radius causes a larger volume to be deformed plastically thereby creating a larger volume for which the radial stress is affected. In each case, the absolute value of the residual stress is decreased when thermal effects are included in the computations.

The influence of thermal effects on the residual stresses left by shot-peening has been studied for typical conditions of the process. It has been shown that the heat generated by thermal effects modifies the residual stress profile, although the temperature remains moderate for a metal (below $200^{\circ} \mathrm{C}$ ). The time sequence of the events is: first, the heat is generated through plastic dissipation during the impact (within about $1 \mu \mathrm{s})$; second, the heat diffuses in the volume, which, in turn, causes a redistribution of the residual stresses. This latter process lasts more than $1 \mathrm{~ms}$. It is further observed that due to the thermal shrinkage during cooling, the absolute value of compressive residual stress decreases near the surface of the specimen.

Rouhaud et al. (2005) shows that in most existing computations, the residual stresses predicted for shot-peening are overestimated. It thus seemed interesting to investigate overlooked physical phenomena to verify if they could explain this discrepancy. Ould et al. (2006) have shown that kinematic hardening could contribute to reducing the absolute value of the predicted residual stresses. It is demonstrated here that thermal effects are not negligible in shot-peening. It could be further noted that the multiplication of impacts will increase the phenomenon.

\section{Acknowledgements}

The authors gratefully acknowledge the Champagne-Ardenne Region and the European Union for their financial support.

\section{RE F E R E N C E S}

Al-Hassani, S.T.S., 1981. Mechanical aspects of residual stress development in shot-peening. In: Niku-lari, A. (Ed.), Proceedings of the First International Conference on Shot-peening, ICSP1, Paris, France. Oxford. Pergamon Press, pp. 583-602.

Al-Obaid, Y.F., 1990. A rudimentary analysis of improving fatigue life of metals by shot-peening. J. Appl. Mech. 57 (2), 307-312.

Al-Obaid, Y.F., 1991. The automated simulation of dynamic non-linearity to shot-peening mechanics. Compos. Struct. 40, 1451-1460.

Al-Obaid, Y.F, 1993. Multiple shot analysis in shot peening using finite elements, in Aliabadi, M.H, Brebbia, C.A (Eds), Computer Methods and Experimental Measurements for Surface Treatments, Computational Mechanics Publications, pp.155-68.
Baragetti, S., Terranova, A., 2000. Non-dimensional analysis of shot peening by means of DoE. Int. J. Mater. Prod. Technol. 15, 131-141.

Fathallah, R., Inglebert, G., Castex, L., 1998. Prediction of plastic deformation and residual stresses induced in metallic parts by shot peening. Mater. Sci. Technol. 14, 631-639.

Harada, Y., Mori, K., 2005. Effect of processing temperature on warm shot-peening of spring steel. J. Mater. Process. Technol. 162-163, 498-503.

Herzog, R., Zinn, W., Scholtes, B., Wohlfahrt, H., 1996. The significance of Almen intensity for the generation of shot-peening residual stresses. In: Champaigne, J. (Ed.), Proceedings of the Sixth International Conference on Shot-peening, ICSP6. San Francisco, USA, pp. 270-281.

Kapoor, R., Nemat-Nasser, S., 1998. Determination of temperature rise during high strain rate deformation. Mech. Mater. 27, $1-12$.

Kirk, D., 2003. Surface heating caused by peening. The Shot Peener 17, 18-20.

Klemenz, M., Schulze, V., Vöhringer, O., Löhe, D., 2006. Finite element simulation of the residual stress states after shot peening. Mater. Sci. Forum 524-525, 349-354.

Kobayashi, M., Matsui, T., Murakami, Y., 1998. Mechanism of creation of compressive residual stress by shot-peening. Int. J. Fatigue 20, 351-357.

Lemaître, J., Chaboche, J.-L., 1994. Mechanics of Materials. Cambridge University Press, Cambridge.

Majzoobi, G.H., Azizi, R., Alavi Nia, A., 2005. A three-dimensional simulation of shot-peening process using multiple shot impacts. J. Mater. Process. Technol. 164-165, 1226-1234.

Meguid, S.A., Shagal, G., Stranart, J.C., 2002. Three-dimensional finite element analysis of peening of strain-rate sensitive materials using multiple impingement model. Int. J. Impact Eng. 27, 119-134.

NW Numerics, 2008. Northwest Numerics and Modeling Inc., web site, www.nwnumerics.com.

Ould, C., Rouhaud, E., François, M., Chaboche, J.L., 2006. A kinematic hardening finite elements model to evaluate residual stresses in shot-peened parts, local measurements by X-ray diffraction. Mater. Sci. Forum 524-525, 161-166.

Petit, J-P., Taine, J., 1998. J. Transferts thermiques Mécanique des fluides anisothermes, cours et données de base, second ed. Dunod Editions.

Pron, H., Henri, J.-F., Flan, B., Lu, J., Offermann, S., Beaudoin, J.L., 2002. Estimation of residual stresses induced by shot-peening. Measurement of the thermal dissipation with an infrared camera. Int. J. Therm. Sci. 41, 369-375.

Rouhaud, E., Deslaef, D., Lu, J., Chaboche, J.-L., 2005. Modeling of residual stress, shot peening. In: Lu, J. (Ed.), Handbook on Residual Stress, vol. 2. Society of Experimental Mechanics, pp. 116-148.

Rouhaud, E., Deslaef, D., 2002. Influence of shot's material on shot-peening, a finite element model. Mater. Sci. Forum 404-407, 153-158.

Rouquette, S., Rouhaud, E., Pron, H., François, M., Bissieux, C., 2005. Thermo-elasto-plastic model for shot-peening: a numerical and experimental approach. In: Schulze, V., Niku-Lari, A. (Eds.), Proceedings of the 9th International Conference on shot-peening. Paris, France, pp. 113-118.

Rosakis, P., Rosakis, A.J., Ravichandran, G., Hodowany, J., 2000. A thermodynamic internal variable model for the partition of plastic work into heat and stored energy in metals. J. Mech. Phys. Solids 48, 581-607.

Schiffner, K., Droste gen. Helling, C., 1999. Simulation of residual stresses by shot-peening. Compos. Struct. 72, 329-340.

Zarka J., Frelat, J., Inglebert, G., Kasmai-Navidi, P., 1990. A New Approach in Inelastic Analysis of Structures, CADLM, Gif sur Yvette. 